\title{
Paeonol enhances thrombus recanalization by inducing vascular endothelial growth factor 165 via ERK1/2 MAPK signaling pathway
}

\author{
SONGSHAN YE ${ }^{1}$, XIANJUAN LIU ${ }^{2}$, BINGYU MAO ${ }^{1}$, LEI YANG $^{1}$ and NUAN LIU ${ }^{1}$ \\ ${ }^{1}$ Department of Medical Experimental Center, Zhang Zhongjing Traditional Chinese Medicine College, \\ Nanyang Institute of Technology, Nanyang, Henan 473004; ${ }^{2}$ Department of Neurology, \\ The First People's Hospital of Nanyang, Nanyang, Henan 473000, P.R. China
}

Received April 24, 2015; Accepted March 10, 2016

DOI: $10.3892 / \mathrm{mmr} .2016 .5135$

\begin{abstract}
Paeonol (2'-hydroxy-4'-methoxyacetophenone) is the major active compound of Mautan cortex and has been demonstrated to inhibit platelet aggregation in previous studies. The current study aimed to elucidate the underlying molecular mechanism of paeonol in recanalizing thrombi. The presence of indicators of prothrombotic state (PTS) in the serum of the model animals were determined by enzyme-linked immunosorbent assay (ELISA) assay and the cytotoxicity of paeonol on human umbilical vein endothelial cell (HUVEC) cultures was estimated by 3-(4,5 dimethylthiazol-2-yl)-2,5-diphenyltetrazolium bromide assay. The possible underlying signaling pathway involved in the interaction between paeonol and vascular endothelial growth factor $165\left(\mathrm{VEGF}_{165}\right)$ was investigated using western blotting. The levels of 6-keto-prostaglandin $\mathrm{F}_{1 \alpha}$, fibronectin, and $\mathrm{VEGF}_{165}$ in serum were significantly upregulated by the treatment of paeonol while the levels of fibrinogen, D-dimer, and thromboxane $\mathrm{B}_{2}$ were significantly downregulated $(\mathrm{P}<0.05)$. With increased paeonol concentration, the cell viability of HUVECs gradually decreased. The results of the western blot analysis demonstrated that paeonol increased the expression levels of phosphorylated-extracellular signal-regulated kinase (ERK1/2) and $\mathrm{VEGF}_{165}$ but had no marked effect on the expression level of ERK1/2. Paeonol has the potential to improve PTS and recanalize thrombi in animal models, which may be by the upregulation of $\mathrm{VEGF}_{165}$ via the ERK1/2 mitogen activated protein kinase signaling pathway. However, this positive effect depended on the concentration of paeonol used, an unsuitably
\end{abstract}

Correspondence to: Professor Bingyu Mao, Department of Medical Experimental Center, Zhang Zhongjing Traditional Chinese Medicine College, Nanyang Institute of Technology, 80 Changjiang Road, Nanyang, Henan 473004, P.R. China E-mail: bingyumao2005@sina.com

Key words: extracellular signal-regulated kinase 1/2, prethrombotic state, paeonol, thrombus, vascular endothelial growth factor 165 high concentration of the compound exerted negative effects on the anti-thrombosis signaling pathways.

\section{Introduction}

Platelets are key in the normal hemostatic process due to injuries to blood vessels, and are important contributors to the pathogenesis of thrombotic disorders resulting from improperly regulated formation of a platelet, or hemostatic, plug (1). Disruption of the endothelium by trauma or by disease, including atherosclerosis, leads to platelets adhering to exposed subendothelial structures and platelet activation. Previous studies have determined that those irregularly activated platelets provide a surface on which coagulation factors assemble and initiate the clotting cascade resulting in thrombin production $(2,3)$. Thus, anti-platelet and anti-coagulant compounds are useful agents for various thrombotic circulatory diseases. However, current anti-platelet and anti-coagulant therapeutic agents have considerable limitations with weak efficacy and associated side effects and more effective therapeutic agents with fewer side effects are required (4-7).

Mautan cortex of Paeonia suffruticosa Andrews is an anti-pyretic, anti-inflammatory agent in traditional Chinese medicine, which has been used for centuries to treat liver disease in China, Japan, and Korea (8-10). The major active compound of Mautan cortex, paeonol (2'-hydroxy-4'-methoxyacetophenone), has been demonstrated to inhibit platelet aggregation in animal models $(8,11)$. Furthermore, previous studies have also identified the inhibitory effect of paeonol on the expression of intercellular adhesion molecule-1 and the activation of the Akt, which contribute to recovery of angiogenesis-associated disease $(12,13)$. Although paeonol has potential as an anti-platelet agent, its application remains limited as the mechanism by which the thrombus is recanalized requires elucidation.

Vascular endothelial growth factor (VEGF) is a specific endothelial cell mitogen and chemotaxin that stimulates in vivo angiogenesis in peripheral and myocardial ischemia (14). Previous studies have demonstrated that injection of a single bolus of $\mathrm{VEGF}_{165}$ protein or gene delivery in an expression plasmid directly into the thrombus shortly following its formation results in increased recanalization and enhanced organization $(14,15)$. Notably, Lee et al $(16)$ have reported the 
interaction between a paeonol derivative, paeonol oxime (PO), and VEGF. A negative effect was reported to be exerted on VEGF $_{165}$ by PO, thus, the present study aimed to investigate the potential of paeonol, which is similarly structured to $\mathrm{PO}$, in regulating the expression of $\mathrm{VEGF}_{165}$.

In the current study, the effect of paeonol on thrombus recanalization using animal and cell models was investigated. The quantity of fibronectin (FN), fibrinogen (FIB), D-dimer (D-D), 6-keto-prostaglandinf $\mathrm{F}_{1 \alpha}$ (6-keto- $\left.\mathrm{PGF}_{1 \alpha}\right)$, thromboxane $\mathrm{B}_{2}$ $\left(\mathrm{TXB}_{2}\right)$, and $\mathrm{VEGF}_{165}$ in the serum of Sprague Dawley (SD) rats was analyzed by a sandwich enzyme-linked immunosorbent assay (ELISA). The cytotoxicity of paeonol on HUVEC cultures was estimated by 3-(4,5 dimethylthiazol-2-yl)-2,5-diphenyltetrazolium bromide (MTT) assay and the possible signaling pathway involved in the interaction between paeonol and VEGF $_{165}$ was evaluated using western blotting. The present study aimed to elucidate the underlying molecular mechanism of paeonol inhibiting platelet aggregation and facilitate the clinical application of this traditional Chinese medicine in improving thrombus recanalization.

\section{Materials and methods}

Materials. Paeonol (2-hydroxy 4-methoxy acetophenone) (purity, >99\%) was purchased from Sigma-Aldrich (St. Louis, MO, USA). The following antibodies were used: Anti-ERK1/2 (rabbit polyclonal; V1141; 1:1,000; Promega Corporation, Madison, WI, USA), phosphorylated (p)-ERK1/2 (rabbit polyclonal; ab50011; 1:800; Abcam, Cambridge, MA, USA), glyceraldehyde 3-phosphate dehydrogenase (GAPDH; rabbit polyclonal; sc-25778; 1:1,200; Santa Cruz Biotechnology, Inc., Dallas, TX, USA), VEGF ${ }_{165}$ (rabbit polyclonal; sc-13083; 1:1,000). The ERK1/2 inhibitor, PD98059 was obtained from EMD Millipore (Billerica, MA, USA). The human umbilical vein endothelial cell (HUVEC) line was purchased from the American Type Culture Collection (Manassas, VA, USA) and grown in Medium 199 supplemented with 20\% fetal bovine serum (Gibco; Thermo Fisher Scientific, Inc., Waltham, MA, USA), $2 \mathrm{mM}$ L-glutamine (Sigma-Aldrich), $5 \mathrm{U} / \mathrm{ml}$ heparin (Sigma-Aldrich), $100 \mathrm{IU} / \mathrm{ml}$ penicillin (Sigma-Aldrich), $10 \mu \mathrm{g} / \mathrm{ml}$ streptomycin (Sigma-Aldrich) and $50 \mu \mathrm{g} / \mathrm{ml}$ endothelial cell growth supplement (American Type Culture Collection). Cells were cultured in a humidified $5 \% \mathrm{CO}_{2}$ incubator at $37^{\circ} \mathrm{C}$ and used for further experiments between passage 3 and 6 .

Grouping of model animals and gavage experiment. The current study was approved by the Ethics Committee of Nanyang Institute of Technology (Nanyang, China). Male SD rats (weight, 350-400 g; age, 18 weeks) were provided by the Laboratory Animal Center of the First Affiliated Hospital of Sun Yat-Sen University (Guangzhou, China) as rat models of thrombosis and housed in cages (10 rats/cage) at room temperature with food and water available ad libitum, and were maintained under at $12 \mathrm{~h}$ light/dark cycle. The rats $(\mathrm{n}=30)$ were randomly grouped into three equal groups (10 in each group), as follows: i) Control group, ii) paeonol group, and iii) aspirin group. In the control group, SD rats received $2 \mathrm{ml} / \mathrm{kg}$ normal saline (Sigma-Aldrich) by gavage every two days for two weeks; in the paeonol group, rats received $1.25 \mathrm{mg} / \mathrm{kg}$ paeonol by gavage every two days for two weeks; and in the aspirin group, rats received $50 \mathrm{mg} / \mathrm{kg}$ aspirin by gavage every two days for two weeks. All the animal experiments were conducted in accordance with the Guide for the Care and Use of Laboratory Animals published by the National Institutes of Health (17).

Serum sample collection and investigation of prothrombotic state (PTS). The rats were anesthetized at the end of the two weeks with $10 \%$ chloral hydrate $(0.3 \mathrm{ml} / 100 \mathrm{~g}$; Sigma-Aldrich $)$ via intraperitoneal injection. Blood samples were collected from the abdominal aorta by opening the abdominal cavity, and immediately centrifuged at $2,200 \mathrm{x}$ g at $4{ }^{\circ} \mathrm{C}$ for $20 \mathrm{~min}$ to separate the serum, which was stored at $-80^{\circ} \mathrm{C}$ for further use. The levels of FN, FIB, D-D, 6-keto- PGF $_{1 \alpha}$, and $\mathrm{TXB}_{2}$, which are associated with PTS, were measured by ELISA. The level of VEGF $_{165}$ was also detected. All ELISAs were conducted using the FN (H140), FIB (F010), D-D (E029), 6-Keto-PGF ${ }_{1 \alpha}$ (H214), TXB (R001) and VEGF $_{165}$ (H044) kits according to the manufacturer's protocols (Nanjing Jiancheng Bioengineering Institute, Nanjing, China): Briefly, plates were coated and incubated overnight at $4^{\circ} \mathrm{C}$ with $3.4 \mathrm{mg} / \mathrm{ml}$ nonbiotinylated 3D5 primary antibody $\left(100 \mu \mathrm{l} /\right.$ well) in $200 \mathrm{mM} \mathrm{NaHCO}{ }_{3}$ (Sigma-Aldrich) at $\mathrm{pH}$ 9.6, and then washed 4 times with phosphate-buffered saline with 0.05\% Tween 20 (PBST; Sigma-Aldrich). Following incubation with $150 \mu \mathrm{l} /$ well blocking buffer (PBST containing $2.5 \%$ gelatin) for $2 \mathrm{~h}$ at $37^{\circ} \mathrm{C}$, the plates were washed 4 times with PBST, and $100 \mu 1$ serum samples (diluted 1:1 with PBS) were added to each well. The plates were incubated at $37^{\circ} \mathrm{C}$ for $2 \mathrm{~h}$. Following washing 4 times with PBST, $100 \mu \mathrm{l} 1 \mu \mathrm{g} / \mathrm{ml}$ biotinylated 3D5 secondary antibody in blocking buffer was added to each well, and incubated at $37^{\circ} \mathrm{C}$ for a further $2 \mathrm{~h}$. The wells were washed 4 times with PBST and incubated with $100 \mu 1 /$ well ExtrAvidin-Alkaline phosphatase (Sigma-Aldrich) in blocking buffer (dilution, 1:5,000) and incubated for $1 \mathrm{~h}$ at $37^{\circ} \mathrm{C}$. Following another 4 washes with PBST, the enzyme substrate alkaline phosphatase yellow (Sigma-Aldrich) was added to each well (100 $\mu \mathrm{l} / \mathrm{well})$ and incubated for $30 \mathrm{~min}$ at $37^{\circ} \mathrm{C}$ for color development. Optical density (OD) values were recorded using a microplate reader at $450 \mathrm{~nm}$ (Multiskan MK3; Thermo Fisher Scientific, Inc.). The content was estimated using a standard curve from serial dilutions.

Cytotoxicity and cell proliferation assay. The MTT assay was performed to determine the cytotoxicity of paeonol on HUVECs. Exponentially growing HUVECs from three to six passages $\left(50 \mu \mathrm{l} ; 2 \times 10^{5}\right.$ cells $\left./ \mathrm{ml}\right)$ were seeded into a 96 -well plate in triplicate. The cells were treated with increasing concentrations of paeonol [ 0 (control), $0.01,0.05,0.1,0.5,1,5,10,20$, and $50 \mu \mathrm{mol} / 1]$ for $24 \mathrm{~h}$ and each concentration was repeated in triplicate. Following paeonol treatment, $5 \mathrm{mg} / \mathrm{ml}$ MTT was added to each well and incubated for $4 \mathrm{~h}$ at $37^{\circ} \mathrm{C}$. MTT is converted into purple-colored formazan in living cells, which was then solubilized with dimethylsulfoxide (Invitrogen; Thermo Fisher Scientific, Inc.), and the OD values in the wells were recorded using the microplate reader at $450 \mathrm{~nm}$. The survival rates (\%) of different treatments were calculated as: (OD value in treatment group - OD value in blank control group) / (OD value in negative control group - OD value in blank control group) $\mathrm{x} 100 \%$.

The highest concentration with the greatest number of cells surviving was $0.5 \mu \mathrm{mol} / 1$, thus, the cell proliferation assay was conducted at this concentration. HUVECs treated 

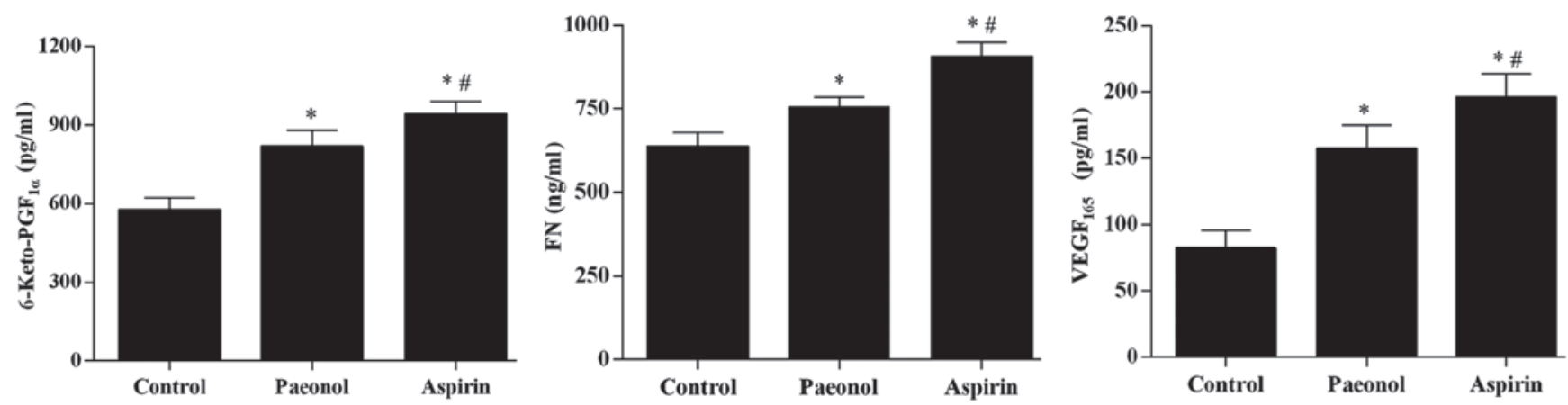

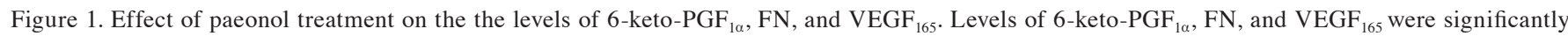
upregulated in the serum of model rats. ${ }^{*} \mathrm{P}<0.05$ vs. the control group, ${ }^{\prime} \mathrm{P}<0.05$ vs. the paeonol group. 6-Keto-PGF $\mathrm{F}_{1 \alpha}, 6$-keto-prostaglandin $\mathrm{F}_{1 \alpha}$; $\mathrm{FN}$, fibronectin; VEGF, vascular endothelial growth factor.
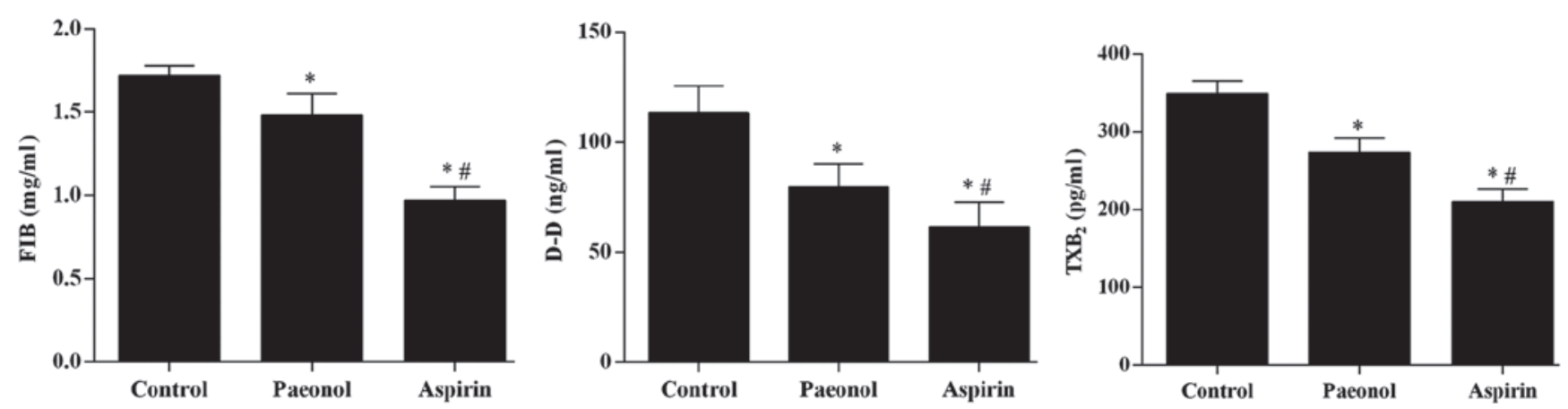

Figure 2. Effect of paeonol treatment on the levels of FIB, D-D, and $\mathrm{TXB}_{2}$. Levels of FIB, D-D, and $\mathrm{TXB}_{2}$ were significantly downregulated in the serum of model rats. ${ }^{\prime} \mathrm{P}<0.05$ vs. the control group, ${ }^{"} \mathrm{P}<0.05$ vs. the paeonol group. FIB, fibrinogen; D-D, D-dimer; $\mathrm{TBX}_{2}$, thromboxane $\mathrm{B}_{2}$.

with $5 \mu \mathrm{mol} / 1$ paeonol were incubated for different times $(0,24,48,72$ and 96 h). Normal HUVECs served as a control to determine the effect of paeonol on the viability of HUVECs over time. The detection of cell proliferation was conducted as described above and the OD values in different wells were recorded using the microplate reader at $450 \mathrm{~nm}$.

Effect of paeonol on expression levels of $V E G F_{165}$ and associated signaling pathways in HUVECs. HUVECs were separated into three groups, as follows: Normal HUVECs; HUVECs incubated with $0.5 \mu \mathrm{mol} / 1$ paeonol; and HUVECs incubated with $0.5 \mu \mathrm{mol} / 1 \mathrm{paeonol}+50 \mu \mathrm{mol} / 1 \mathrm{PD} 98059$. For each treatment group, the protein expression levels of $\mathrm{VEGF}_{165}, \mathrm{ERK} 1 / 2$, and pERK1/2 were detected in cell samples after $24 \mathrm{~h}$ incubation. GAPDH served as a loading control for western blot analysis. Total proteins were extracted using sodium dodecyl sulfate (SDS) lysis buffer (Beyotime Institute of Biotechnology, Haimen, China) on ice for $30 \mathrm{~min}$ and the protein concentration was determined using the Bicinchoninic Protein Assay kit (Pierce Biotechnology, Inc., Rockford, IL, USA). All the extracts were boiled with loading buffer for 5 min prior to separation with SDS-polyacrylamide gel electrophoresis on $10 \%$ gels at $160 \mathrm{~V}$ for $60 \mathrm{~min}$. Proteins were transferred onto polyvinylidene difluoride membranes. The membranes were washed with Tris-buffered saline with Tween 20 (TBST; Sigma-Aldrich) for $20 \mathrm{~min}$, and the procedure was repeated three times. The membranes were incubated with primary antibodies overnight at room temperature. Following three additional washes with
TBST, the horseradish peroxidase-labeled goat anti-rabbit $\operatorname{IgG}$ secondary antibodies (Beyotime Institute of Biotechnology) were added and the membrane was incubated for $4 \mathrm{~h}$ at $37^{\circ} \mathrm{C}$. Following three final washes with TBST, the blots were developed using BeyoECL Plus reagent (Beyotime Institute of Biotechnology) and the results were detected in the Gel Imaging system (Bio-Rad Laboratories, Inc., Hercules, CA, USA).

Statistical analysis. All the data were expressed as the mean \pm standard deviation. Multiple comparisons were conducted using Fisher's Least Significant Difference method. All the statistical analyses were conducted using SPSS version 19.0 (IBM SPSS, Armonk, NY, USA). P<0.05 was considered to indicate a statistically significant difference.

\section{Results}

Paeonol improves the PTS and increases VEGF expression in rat models of thrombosis. Using an ELISA, the levels of 6-keto-PGF $\mathrm{Pa}_{1 \alpha}, \mathrm{FN}$, and $\mathrm{VEGF}_{165}$ in serum were determined to be significantly upregulated by treatment with paeonol $(\mathrm{P}<0.05)$, however, the effect was smaller than that of aspirin treatment (Fig. 1). The levels of FIB, D-D, and $\mathrm{TXB}_{2}$ were significantly downregulated by paeonol $(\mathrm{P}<0.05)$, however, the effect was also smaller than that of aspirin treatment (Fig. 2).

Paeonol exerts a weak cytotoxic effect on HUVECs and improves cell proliferation. With increased concentration of 


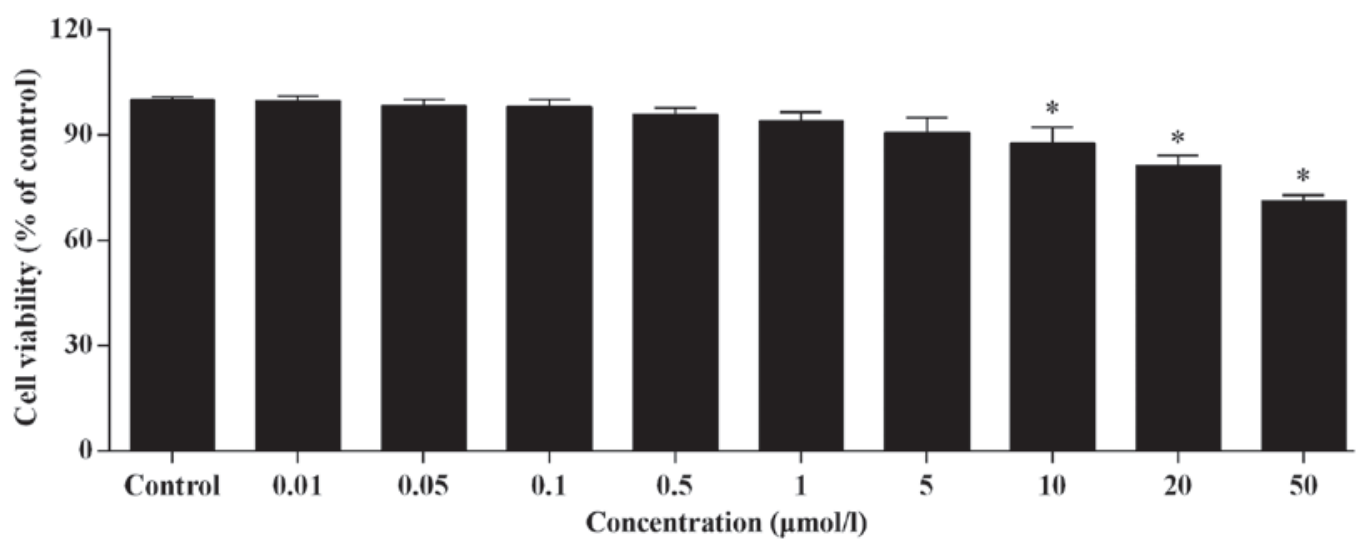

Figure 3. Effect of paeonol treatment on the viability of human umbilical vein endothelial cells. The cells were incubated with different concentrations of paeonol for $24 \mathrm{~h}$. The cell viability was assayed by the 3-(4,5 dimethylthiazol-2-yl)-2,5-diphenyltetrazolium bromide method and results are expressed as the mean \pm standard error from three independent experiments. ${ }^{*} \mathrm{P}<0.05$ vs. the control group.

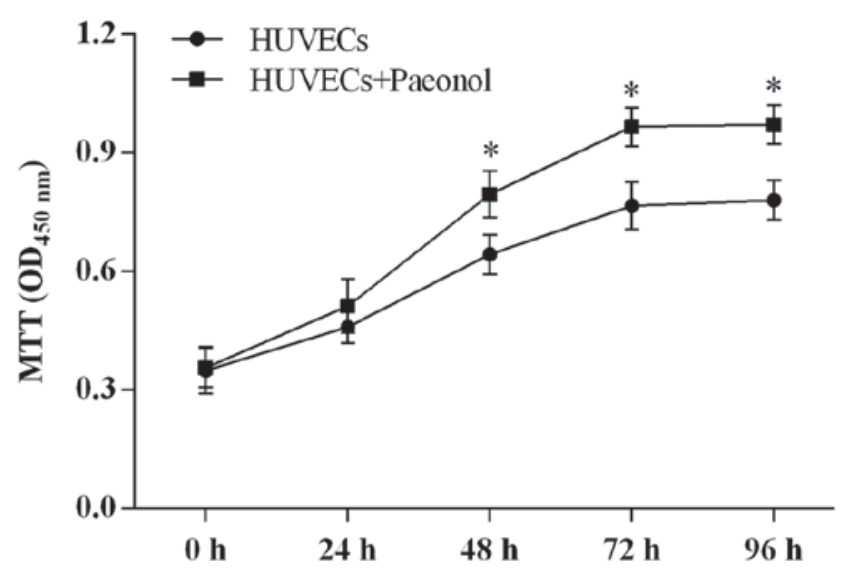

Figure 4. Effect of paeonol treatment $(0.5 \mu \mathrm{mol} / \mathrm{l})$ on the proliferative ability of HUVECs. The cell proliferative ability of HUVECs was improved compared with control HUVECs. HUVEC, human umbilical vein endothelial cells; MTT, 3-(4,5 dimethylthiazol-2-yl)-2,5-diphenyltetrazolium bromide; OD, optical density. " $\mathrm{P}<0.05$ vs. the HUVECs group.

paeonol, the cell viability of HUVECs decreased gradually (Fig. 3). No significant difference was detected for paeonol concentration $<0.5 \mu \mathrm{mol} / 1$. However, at concentrations $>0.5 \mu \mathrm{mol} / 1$, a significant difference in cell viability was observed $(\mathrm{P}<0.05$; Fig. 3). At a concentration of $50 \mu \mathrm{mol} / 1$ paeonol, the cell viability was $>70 \%$, which indicates a safe result.

Based on the results of the MTT assay, $0.5 \mu \mathrm{mol} / 1$ was determined as the suitable concentration for further experiments. Paeonol at this concentration significantly improved the cell proliferation ability in a time-dependent manner compared with normal HUVECs ( $\mathrm{P}<0.05$; Fig. 4).

Treatment with paeonol activated the phosphorylation of ERK1/2 and upregulated the expression of $V E G F_{165}$. To elucidate the signaling pathway involved in the anti-thrombotic effect exerted by paeonol, the effect of paeonol on the expression levels of ERK1/2, p-ERK1/2, and VEGF $_{165}$ was investigated. As presented in Fig. 5, the expression levels of p-ERK1/2 and VEGF $_{165}$ were upregulated in HUVECs. Treatment with the ERK1/2 signaling pathway inhibitor, PD98059

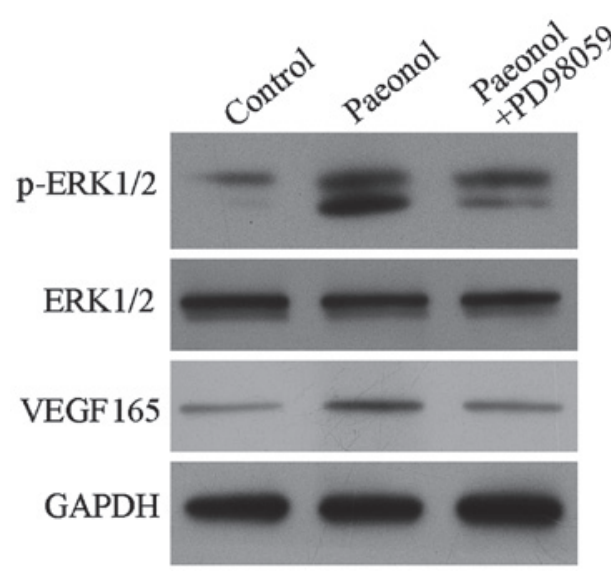

Figure 5. Effect of paeonol treatment on the anti-thrombosis associated pathway. Paeonol activated the phosphorylation of ERK1/2 and enhanced the expression of VEGF 165. ERK1/2, extracellular signal-regulated kinase; p-ERK1/2, phosphorylated ERK1/2; VEGF, vascular endothelial growth factor.

markedly blocked the effect of paeonol on p-ERK1/2 and VEGF $_{165}$.

\section{Discussion}

Platelet activation and thrombus formation are important in pathophysiology of ischemic events, thus, anti-platelet therapeutic strategies are useful in preventing acute thromboembolic artery occlusion. Anti-platelet therapeutic agents, including aspirin, ticlopidine, and dipyridamole are clinically used, however, these therapeutic agents result in a number of side effects (18) including stent thrombosis and acute myocardial infarction (19). Paeonol is a nonsteroidal anti-inflammatory, with a structure similar to aspirin. Previous studies have reported beneficial effects of paeonol as an anti-angiogenic, anti-metastatic and anti-platelet agent $(8,11)$. However, more investigation into the underlying mechanism of paeonol in recanalizing thrombi is required.

In the present study, the anti-platelet effect of paeonol was investigated in SD rats. The ELISA assays demonstrate improved PTS by changes in expression of FN, FIB, D-D, 
6-keto- $\mathrm{PGF}_{1 \alpha}$, and $\mathrm{TXB}_{2}$ in the paeonol-treated group. Although treatment with aspirin was observed to be more effective, the concentration of aspirin was higher than that of paeonol. As paeonol has demonstrated fewer side effects, the concentration of paeonol used clinically may be adjusted to a level with comparable or stronger effects than aspirin. However, more comprehensive animal and clinical studies are required to be conducted in the future. The cytotoxicity of paeonol on HUVECs was assessed by MTT assay. It was demonstrated that the proliferative ability of the cells was improved by paeonol with little cytotoxicity. Although paeonol suppressed the cell proliferation in a concentration-dependent manner when the concentration was $>0.5 \mu \mathrm{mol} / 1$, at a paeonol concentration of $50 \mu \mathrm{mol} / 1$, cell viability of HUVECs remained at $>70 \%$.

Gene therapy with VEGF has been used to promote revascularization in the ischemic heart and in peripheral vascular disease with some success (20-22). VEGF $_{165}$ release by transfection of a plasmid containing the $\mathrm{VEGF}_{165}$ gene to improve thrombus recanalization has also been reported (23). Lee et al (16) focused on the interaction between a derivative of paeonol and VEGF, PO was demonstrated to suppress the expression of VEGF at a concentration of $70 \mu \mathrm{mol} / \mathrm{l}$. Negative effects of this derivative are hypothesized to be due to the high concentration used in the previous study. Thus, in the current study, based on the results of the MTT assay, a more suitable concentration was selected for the assessment of the effects of paeonol on anti-thrombosis associated signaling pathways. At a concentration of $0.5 \mu \mathrm{mol} / 1$, paeonol activated the phosphorylation of ERK1/2 and upregulated the expression levels of VEGF. However, exposure to paeonol had no observable effect on the expression levels of ERK1/2 in HUVECs.

The role of ERK in transcriptional and post-transcriptional regulation of VEGF is well-defined (24). A previous study demonstrated that the ERK signaling pathway is also activated during hypoxia in human endothelial cells (25). Notably, the results from the present study were contrary to the previous study of Nizamutdinova et al (26), which demonstrated an inhibitory effect of paeonol on the ERK1/2 signaling pathway. The concentration of paeonol used in the present and previous studies was compared, and it was identified that in the MTT assay conducted in the current study, the cell viability was significantly decreased by paeonol at concentrations $>1 \mu \mathrm{mol} / 1$, and in Nizamutdinova et al (26), the expression levels of p-ERK1/2 was inhibited by paeonol $>1 \mu \mathrm{mol} / 1$. In the two studies, the expression levels of ERK1/2 were not influenced by paeonol. In addition, Lee et al (16) showed that the expression levels of VEGF were not downregulated by $\mathrm{PO}$ at concentration up to $34.5 \mu \mathrm{mol} / \mathrm{l}$. Thus, the ERK signaling pathway may also activate other transcription factors that may mediate VEGF induction by paeonol. Furthermore, the concentration of paeonol in clinical application should be carefully determined, accounting for the expression levels of anti-thrombosis associated factors and cell viability.

In conclusion, paeonol may improve the PTS and recanalize thrombi in animal models, which may be by the upregulation of $\mathrm{VEGF}_{165}$ via the ERK1/2 MAPK signaling pathway. However, this positive effect depended on the concentration of paeonol used, a unsuitably high concentration of the compound resulted in a negative effect on the anti-thrombosis signaling pathways. The present study aimed to elucidate the underlying mechanism of paeonol in recanalizing thrombi, and more comprehensive animal and clinical studies should be conducted in order to determine a practical concentration of paeonol for clinical applications to improve the anti-platelet and anti-coagulant therapeutic strategies for various thrombotic circulatory diseases.

\section{References}

1. Packham MA: Role of platelets in thrombosis and hemostasis. Can J Physiol Pharmacol 72: 278-284, 1994.

2. Dupont AG, Gabriel DA and Cohen MG: Antiplatelet therapies and the role of antiplatelet resistance in acute coronary syndrome. Thromb Res 124: 6-13, 2009.

3. Konkle BA, Simon D and Schafer AI: Hemostasis, thrombosis, fibrinolysis and cardiovascular disease. In: Braunwald's Heart Disease: A Textbook of Cardiovascular Medicine. Libby P, Bonow RO, Mann DL and Zipes DP (eds). 8th edition. Saunders Elsevier, Philadelphia, PA, pp2049-2078, 2008.

4. Schrör K: Antiplatelet drugs. A comparative review. Drugs 50: 7-28, 1995.

5. Ni H and Freedman J: Platelets in hemostasis and thrombosis: Role of integrins and their ligands. Transfus Aphe Sci 28: 257-264, 2003.

6. Barrett NE, Holbrook L, Jones S, Kaiser WJ, Moraes LA, Rana R, Sage T, Stanley RG, Tucker KL, Wright B and Gibbins JM: Future innovations in anti-platelet therapies. Br J Pharmacol 154: 918-939, 2008.

7. Bird JE, Giancarli MR, Allegretto N, Barbera F, Wong P, Schumacher WA, Ogletree ML and Seiffert D: Prediction of the therapeutic index of marketed anti-coagulants and anti-platelet agents by guinea pig models of thrombosis and hemostasis. Thromb Res 123: 146-158, 2008.

8. Lin HC, Ding HY, Ko FN, Teng CM and Wu YC: Aggregation inhibitory activity of minor acetophenones from Paeonia species. Planta Med 65: 595-599, 1999.

9. Yasuda T, Kon R, Nakazawa T and Ohsawa K: Metabolism of paeonol in rats. J Nat Prod 62: 1142-1144, 1999.

10. Chou TC: Anti-inflammatory and analgesic effects of paeonol in carrageenan-evoked thermal hyperalgesia. Br J Pharmacol 139: 1146-1152, 2003

11. Koo YK, Kim JM, Koo JY,Kang SS, Bae K, Kim YS, Chung JH and Yun-Choi HS: Platelet anti-aggregatory and blood anti-coagulant effects of compounds isolated from Paeonia lactiflora and Paeonia suffruticosa. Pharmazie 65: 624-628, 2010.

12. Lin C, Lin HY, Chen JH, Tseng WP, Ko PY, Liu YS, Yeh WL and Lu DY: Effects of paeonol on anti-neuroinflammatory responses in microglial cells. Int J Mol Sci 16: 8844-8860, 2015.

13. Wen FS, Zhao HW, Jin XG, Yu HZ: Effect of paeonol on intercellular adhesion molecule 1 expression after cerebral ischemia reperfusion in rats. Chin J Clin Rehabil 8, 3792-3793: 2004.

14. Neufeld G, Cohen T, Gengrinovitch S and Poltorak Z: Vascular endothelial growth factor (VEGF) and its receptors. FASEB J 13: 9-22, 1999.

15. Waltham M, Burnand KG, Collins M, McGuinness CL, Singh I and Smith A: Vascular endothelial growth factor enhances venous thrombus recanalisation and organisation. Thromb Haemost 89: 169-176, 2003.

16. Lee HJ, Kim SA, Lee HJ, Jeong SJ, Han I, Jung JH, Lee EO, Zhu S, Chen CY and Kim SH: Paeonol oxime inhibits bFGF-induced angiogenesis and reduces VEGF levels in fibrosarcoma cells. PLoS One 5: e12358, 2010

17. National Research Council: Guide for the Care and Use of Laboratory Animals. 7th edition. National Academy Press, Washington, DC, 1996.

18. Lee, KS, Oh KW, Bae KH, Kim YH, Lee MY, Cho MR, Jin YR and Yun YP: Inhibitory effects of moutan cortex radicis extracts and paeonol on rabbit platelet aggregation. Journal of Food Hygiene and Safety 19: 167-170, 2004.

19. Kovacic JC, Lee P, Karajgikar R, Baber U, Narechania B, Suleman J, Moreno PR, Sharma SK and Kini AS: Safety of temporary and permanent suspension of anti-platelet therapy after drug eluting stent implantation in contemporary "real-world" practice. J Interv Cardiol 25: 482-492, 2012. 
20. Folkman J: Angiogenic therapy of the human heart. Circulation 97: 628-629, 1998.

21. Folkman J: Therapeutic angiogenesis in ischemic limbs. Circulation 97: 1108-1110, 1998.

22. Baumgartner I, Pieczek A, Manor O, Blair R, Kearney M, Walsh K and Isner JM: Constitutive expression of phVEGF165 after intramuscular gene transfer promotes collateral vessel development in patients with critical limb ischemia. Circulation 97: 1114-1123, 1998.

23. Waltham M, Burnand K, Fenske C, Modarai B, Humphries J and Smith A: Vascular endothelial growth factor naked DNA gene transfer enhances thrombus recanalization and resolution. J Vasc Surg 42: 1183-1189, 2005 .
24. Milanini J, Richard DE, Berra E, Gothié E, Viñals F and Pouysségur J: Signaling angiogenesis via p42/p44 MAP kinase cascade. Ann NY Acad Sci 902: 187-200, 2000.

25. Minet E, Arnould T, Michel G, Roland I, Mottet D, Raes M, Remacle J and Michiels C: ERK activation upon hypoxia: Involvement in HIF-1 activation. FEBS Lett 468: 53-58, 2000.

26. Nizamutdinova IT, Oh HM, Min YN, Park SH, Lee MJ, Kim JS, Yean MH, Kang SS, Kim YS, Chang KC and Kim HJ: Paeonol suppresses intercellular adhesion molecule-1 expression in tumor necrosis factor-alpha-stimulated human umbilical vein endothelial cells by blocking p38, ERK and nuclear factor-kappaB signaling pathways. Int Immunopharmacol 7: 343-350, 2007. 